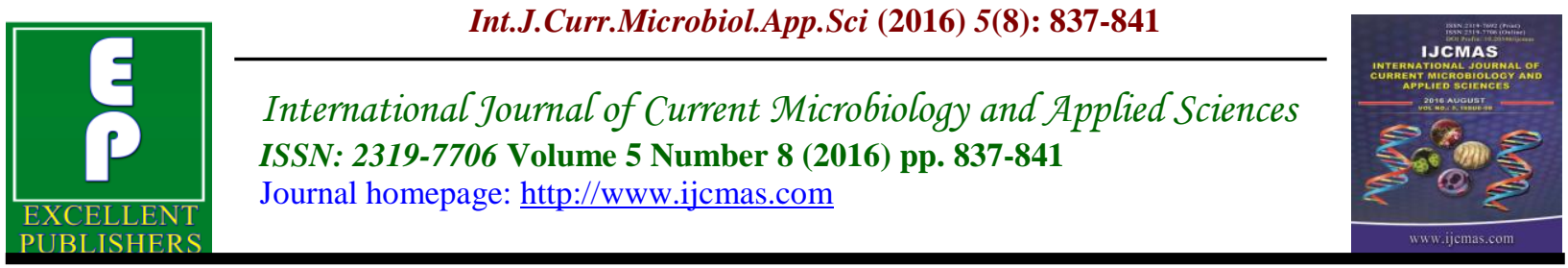

Short Communications

http://dx.doi.org/10.20546/ijcmas.2016.508.094

\title{
Viral Aetiologies of Acute Respiratory Tract Infections among Children in Andaman and Nicobar Archipelago India
}

\author{
Suriya Mullaikodi", Itta Krishna Chaaithanya", \\ Nagarajan Muruganandam" ${ }^{\#}$ and Paluru Vijayachari* \\ Regional Medical Research Centre (ICMR), Port Blair, \\ Andaman \& Nicobar Islands, 744101 India \\ *Corresponding author \\ \# equally contributed to the work
}

\section{Keywords}

Respiratory Tract Infections,

Andaman \&

Nicobar Islands, Viral Aetiologies.

Article Info

Accepted:

18 July 2016

Available Online:

10 August 2016

\section{A B S T R A C T}

Acute respiratory tract infections (ARI) are the most common illnesses in young children, irrespective of age or gender, and ARI accounts for one fifth of all deaths in children $<5$ years. The main viral causes of ARI were RSV identified in $10.14 \%(246 / 2444)$, followed by Adeno viruses (8\%, 197/2444), influenza viruses (3.9\%, 96/2444), HMPV $(2.2 \%, 54 / 2444)$ and Para influenza virus $3(1.1 \%, 27 / 2444)$ from sample collected from hospitals in Andaman and Nicobar archipelago India. To the best of our knowledge, this is the first study discussed about the prevalence of various aetiologies in Andaman \& Nicobar Islands.

\section{Introduction}

Acute respiratory tract infections (ARI) is the foremost cause of pediatric mortality worldwide with a substantial number of deaths (one fifth of all death) occurring in developing countries (Williams et al., 2002). The frequency of ARI is similar in both developed and developing countries, mortality is approximately 1.9 million in developing countries (10 - 50 times higher) and India accounts $20 \%$ of this (Broor et al., 2007). ARI caused by diverse group of complex aetiologies where, viral infections are most frequent and responsible for a significant morbidity and mortality in children (Iwane et al., 2004).
Recent study in India and other studies by elsewhere (Broor et al., 2007) have confirmed that, among respiratory viruses Respiratory syncytial virus (RSV), Human para influenza viru (HPIF) and influenza viruses $\mathrm{A}$ and $\mathrm{B}, \mathrm{RSV}$ has been documented to be the most common pathogen (Indumathi et al., 2015).Among these viruses RSV is a major cause of severe respiratory disease in both infants and elderly persons.

The pattern of respiratory tract infections is variable and is related to factors that include region, season, and year (Yanqin et al., 2013). Limited studies are exists on role of 
viruses in the aetiology of ARI in India (Kloene et al., 1970; Mathur A et al., 1979). The present study was undertaken to describe the molecular epidemiology of the ARI due to viruses from sample collected from hospitals in Andaman and Nicobar archipelago India.

Andaman and Nicobar Islands (A\&N Islands), an archipelago is situated in the Bay of Bengal, about 1,200 km southeast of peninsular India, is a Union Territory of India. The Emergence of RSV infection was noticed in 2006 (RMRC annual Report 2007) but there is no further documentation.

Present observation are noted in a surveillance project on Establishment of Grade I Virology laboratory to investigate the various viral aetiologies circulating in and around in A\&N Islands. The study was conducted in during June 2012 to June 2014 based at two hospitals (G.B Path Hospital, only one Referral hospital and Chirayu Child Care Hospital, Private hospitals) in Port Blair, Headquarters of A\&N Islands.

\section{Experimental procedures}

Specimens (Nasopharyngeal swabs) were collected from the patients $(<5$ years $)$ hospitalized and from those attended to the out-patient department (OPD) with ARI, along with clinical and demographic details after obtaining informed written consent/Assent following approval of the Institutional Ethics committees of the Regional Medical Research Centre (ICMR), Port Blair, A\&N Islands.

Upon receipt, specimens were vortexed and centrifuges at $1,500 \mathrm{Xg}$ for 10 minutes at $4^{\circ} \mathrm{C}$, and the supernatants were stored.From the collected supernatant,viral RNA was extracted using QIAamp Viral RNA extraction kit (Qiagen Sciences, USA) and converted to complementary DNA (cDNA) by reverse transcription polymerase chain reaction (Applied Biosystems, Foster City, USA) using random primers (Applied Biosystems) and conditions as described by the manufacturer. Further cDNA was amplified with specific primers for the presence of RSV type A and B, Influenza A and $\mathrm{B}$ viruses, PIV1, 2 and 3, hMPV and AdV as described elsewhere (Bharaj et al., 2009).

Further, amplicons were purified using QIA quick PCR purification kit (QIA quick gel extraction kit, QIAGEN, Germany) and cycle sequenced (Applied Biosystems, CA). The sequences so obtained were compared to reference strains by using the BLAST program. Obtained were data were analysed by using online software.

\section{Results and Discussion}

A total of 2444 children under five years were diagnosed with ARI from June 2012 to June 2014 from the two hospitals. Of these 2444 children, majority $1405(57.5 \%)$ were males and 1039(42.5\%) were females. One or two viral pathogens were detected in respiratory specimens of 620 of 2444 (27\%) patients.

The main viral causes of ARI were RSV identified in 10.14\% (246/2444), followed by Adeno viruses $(8 \%, 197 / 2444)$, influenza viruses $(3.9 \%, 96 / 2444)$, HMPV (2.2\%, $54 / 2444)$ and Para influenza virus $3(1.1 \%$, 27/2444).Infections with two different viruses were found in1.6\% (38/2444) (Table 1).

RSV and adeno viruses were the leading causes of single infections, followed by influenza A, hMPV and Para influenza 3. More number of RSV cases were recorded in the month of October. 
Table.1 Demographic and clinical characteristics and virus positivity of patients with ARI (N = $620 / 2444(27 \%))$

\begin{tabular}{|c|c|c|c|c|c|c|c|}
\hline \multirow[t]{2}{*}{ Parameters } & \multirow{2}{*}{$\begin{array}{c}\text { Positives } \\
\text { cases }\end{array}$} & \multirow{2}{*}{$\begin{array}{c}\text { Negative } \\
\text { cases }\end{array}$} & \multicolumn{5}{|c|}{ Virus positives } \\
\hline & & & RSV & Influenza & Parainfluenza & HMPV & Adeno virus \\
\hline \multicolumn{8}{|l|}{ Gender } \\
\hline Male & $337(24)$ & $1068(76)$ & $141(57.3)$ & $43(44.7)$ & $18(66.6)$ & $22(40.7)$ & $113(57.37)$ \\
\hline Female & $283(27)$ & $756(73)$ & $105(42.6)$ & $53(55.2)$ & $9(33.3)$ & $32(59.2)$ & $84(42.63)$ \\
\hline Age Groups (in Months) & & & $\mathrm{N}=246$ & $\mathrm{~N}=96$ & $\mathrm{~N}=27$ & & $\mathrm{~N}=197$ \\
\hline $1-12$ & $270(25.7)$ & $782(74.3)$ & $119(48.3)$ & $35(36.4)$ & $20(74.1)$ & $23(42.5)$ & $73(37)$ \\
\hline 13-24 & $144(29.4)$ & $346(70.6)$ & $62(25.2)$ & $19(19.7)$ & $5(18.5)$ & $12(22.2)$ & $46(23.3)$ \\
\hline $25-36$ & $103(28)$ & $265(72)$ & $42(17)$ & $10(10.4)$ & $2(7.4)$ & $13(24)$ & $36(18.2)$ \\
\hline $37-48$ & $61(24.9)$ & $184(75.1)$ & $16(6.5)$ & $9(9.3)$ & - & $6(11.1)$ & $30(15.2)$ \\
\hline $49-60$ & $42(14.5)$ & $247(85.5)$ & $7(2.8)$ & $23(23.9)$ & - & - & $12(6)$ \\
\hline \multicolumn{8}{|l|}{ Clinical Presentation } \\
\hline Temperature median(IQR) & & & $38(37.7-38.2)$ & $38.8(38.8-8.8)$ & $38.6(38.2-39)$ & $37.5(37.5-37.5)$ & $\begin{array}{c}37.9(37.4- \\
38.5)\end{array}$ \\
\hline $\begin{array}{l}\text { Duration of illness } \\
\text { median(IQR) }\end{array}$ & & & $6(3-7)$ & $4(3-5)$ & $3(2-4)$ & $3(2-5)$ & $3(2-6)$ \\
\hline Cough & $558(24.7)$ & $1699(75.3)$ & 242(98.3) & $77(80.2)$ & $19(70.3)$ & $40(74)$ & $180(91.3)$ \\
\hline Fever & $528(24.9)$ & $1589(75.1)$ & $207(84.1)$ & $83(86.4)$ & $22(81.4)$ & $36(66.6)$ & $180(91.3)$ \\
\hline Running nose & $398(25.4)$ & $1168(74.6)$ & $136(55.2)$ & $76(79.1)$ & $12(44.4)$ & $32(59.2)$ & $142(72)$ \\
\hline Nasal congestion & $362(29.1)$ & $884(70.9)$ & $152(61.7)$ & $39(40.6)$ & $17(62.9)$ & $23(42.5)$ & $131(66.4)$ \\
\hline Wheeze & $451(40.2)$ & $671(59.8)$ & $246(100)$ & $69(71.8)$ & $20(74)$ & - & $116(58.8)$ \\
\hline Vomiting & $166(33.4)$ & $331(66.6)$ & $109(44.3)$ & $13(13.5)$ & - & $9(16.6)$ & $35(17.7)$ \\
\hline Cold & $158(36)$ & $281(64)$ & $60(24.3)$ & $21(21.8)$ & $3(11.1)$ & $18(33.3)$ & $56(28.4)$ \\
\hline Breathlessness & $144(60.8)$ & $93(39.2)$ & $102(41.4 \%)$ & $18(18.7)$ & $7(25.9)$ & $5(9.2)$ & 12( 6$)$ \\
\hline Chills & $36(28.8)$ & $89(71.2)$ & $12(4.8 \%)$ & $6(6.2)$ & $5(18.5)$ & $3(5.5)$ & $10(5)$ \\
\hline Headache & $20(40.8)$ & $29(59.2)$ & $20.8 \%)$ & $4(4.1)$ & $2(7.4)$ & $5(9.2)$ & $7(3.5)$ \\
\hline
\end{tabular}


Of the total positive for various virus aetiologies part of the sample for each virus were further processed for sequence analysis for molecular characterization. Part of the nucleotide sequencing of $\mathrm{N}$ gene isolated from RSV positive samples were carried out and analysis of the sequences by BLAST confirmed $100 \%$ similarity with the sequences of these genes isolated from RSV A (JF920059 genotype GA5) and RSV B (JN032122 genotype BA) available at NCBI data base. The Adenovirus sequences isolated from these Islands had $100 \%$ matched with serotype 1 (JF 712981; Species C). Phylogenetic analysis of hMPV circulating in these Islands were identified as hMPV A2 (subtype 2; Genotype A) and matched with reference sequence (FJ168779) from data base. Sequence analysis confirms the presence of para influenza virus 3 is circulating in the islands. Sequence analysis on Influenza virus could not be done, RT PCR confirms the Influenza $A$ virus is circulating.

Andaman Islands are the tourist place for both Indian and International vacationers. Influx of more population is anticipated in all the time, and there is transmissions of various viral infections are also expected.In the present study considered only the hospitalized and OPD patients with suspected viral infections were examined, the isolation rate of RSV in this study was dominant compared with other viruses. The study provides the baseline information on the prevalence and epidemiology of the various viral aetiologies in hospitalized children with ARTI. To the best of our knowledge, this is the first study discussed about the prevalence of various aetiologies in these Andaman \& Nicobar Islands. Further, detailed studies are required on viral aetiologies towards RSV, and its immunology in the susceptible population of among these islands.

\section{Acknowledgments}

The current study formed a part of the activities under the Establishment of Grade I Diagnostic Virology at the Regional Medical Research Centre (ICMR), Port Blair which is being supported by extramural grant from the Indian Council of Medical Research (Ref. letter No. 5/8/7/16/2010ECD-I). The authors are grateful to the Directorate of Health Services, Andaman \& Nicobar Administration for extending support during the conduct of study.

\section{References}

Bharaj, P., Sullender, W.M., Kabra, S.K., Mani, K., Cherian, J., Tyagi, V., Chahar, H.S., Kaushik, S., Dar, L., Broor, S. 2009. Respiratory viral infections detected by multiplex PCR among pediatric patients with lower respiratory tract infections seen at an urban hospital in Delhi from 2005 to 2007. Virol. J., 26, 6: 89.

Broor, S., Bharaj, P. 2007.Avian and human metapneumovirus. Ann. NY. Acad. Sci., 1102: 66-85.

Indumathi, C.P., Gunanasekaran, P., Kaveri, K., Arunagiri, K., Mohana, S., Sheriff, A.KSureshBabu, B.V., Padmapriya, P., Senthilraja, R., Fathima, G. 2015. Isolation \& molecular characterization of human parainfluenza virus in Chennai, India. Indian J. Med. Res., 5: 583-90.

Iwane, M.K., Edwards, K.M., Szilagyi, P.G., Walker, F.J., Griffin, M.R., Weinberg, G.A. 2004. Populationbased surveillance for hospitalizations associated with respiratory syncytial virus, influenza virus, and parainfluenza viruses among young children. J. Pediatr., 113: $1758-1764$. 
Kloene, W., Bang, F.B., Chakraborty, S.M., Cooper, M.R., Kulemann, H., Shah, K.V., Ota, M. 1970. A two year respiratory virus survey in four villages in West Bengal. Am $J$ Epidemiol., 92, 307-20.

Lu, Y., Wang, S., Zhang, L., Xu, C., Bian, C., Wang, Z., Ma, Y., Wang, K., Ma, L., Meng, C., Ni, C., Tong, J., Li, G., Han, J. 2013.Epidemiology of Human Respiratory Viruses in Children with Acute Respiratory
Tract Infections in Jinan, China. Clin. Dev. Immunol., 210490.

Mathur, A., Singh, U.K., Tandon, H.O., Chaturvedi, U.C. 1979. Pattern of some viruses in acute respiratory illness during 1972-73 at Lucknow. Indian J. Med. Res., 69: 546-52.

Williams, B.G., Gouws, E., Boschi-Pinto, C., Bryce, J., Dye, C. 2002. Estimates of world-wide distribution of child deaths from acute respiratory infections. Lancet Infect. Dis., 2: 2532.

\section{How to cite this article:}

Suriya Mullaikodi, Itta Krishna Chaaithanya, Nagarajan Muruganandam and Paluru Vijayachari. 2016. Viral Aetiologies of Acute Respiratory Tract Infections among Children in Andaman and Nicobar Archipelago India. Int.J.Curr.Microbiol.App.Sci. 5(8): 837-841. doi: http://dx.doi.org/10.20546/ijcmas.2016.508.094 